\title{
THE INFLUENCE OF A GEOMETRIC DEFECT ON THE LIGHT PROPAGATION THROUGH TWO ONE-DIMENSIONAL NONLINEAR PHOTONIC LATTICES
}

Marija T Stojanović Krasićc ${ }^{*}$, Slavica J. Jovanović², Ana M. Mančić ${ }^{3}$

(ORIGINAL SCIENTIFIC PAPER)

UDC 535.317.2:530.182

\footnotetext{
${ }^{1}$ Faculty of Technology, University of Niš, Leskovac, Serbia.

${ }^{2}$ Faculty of Natural Sciences and Mathematics, University of Priština, Kosovska Mitrovica, Serbia.

${ }^{3}$ Faculty of Natural Sciences and Mathematics, University of Niš, Niš, Serbia.
}

The propagation of the light beam through the composite lattice formed of two structurally different one-dimensional nonlinear photonic lattices was analyzed numerically. The properties of light propagation through nonlinear and linear composite lattices were compared too. Depending on the position of the input beam, the value of the transverse kick and nonlinearity strength different regimes of light propagation through nonlinear composite lattices such as transmission, partial reflection and capturing of light was identified.
Keywords: interface, defect modes, nonlinear lattices

\section{Introduction}

Photonic lattices $(\mathrm{PL})$ are optical systems of weakly coupled waveguide (WG) arrays which are suitable for manipulation and control of light propagation. Their periodic modulation of the refractive index enables the existence of the appropriate band - gap frequency spectrum which defines the light propagation [1]. The band - gap frequency spectrum and the light propagation can be redefined by the presence of structural defects which can enable the formation of defect modes [2 - 5]. Different features can be seen as structural defects: an interface between two lattices, a WG whose width differs from other WGs in the array or the separation between two WGs in the array different than the separation between other WGs. Structural defects are widely analyzed not only in PLs, but also in other settings, such as e-biology [6] and solid state physics [7].

In this work, we have numerically analyzed the dynamics of the light beam propagating through the composite $\mathrm{PL}$ consisting of two structurally different nonlinear one-dimensional (1D) lattices. The interface of two lattices is marked as a geometric defect (GD). Varying the input parameters, different dynamical regimes have been identified including full transparency, blockade of light propagation by reflection from GD, as well as trapping of the light on the GD.

The paper is organized in the following way. The mathematical model of wave propagation through the system is formulated in Section 2. Numerical results are presented in Section 3. In Section 4, the conclusions have been briefly summarized.

\section{Model equations}

Light propagation through the nonlinear composite PL consisting of two structurally different sub - lattices, marked as $A$ and $B$ is analyzed numerically (see Figure 1).

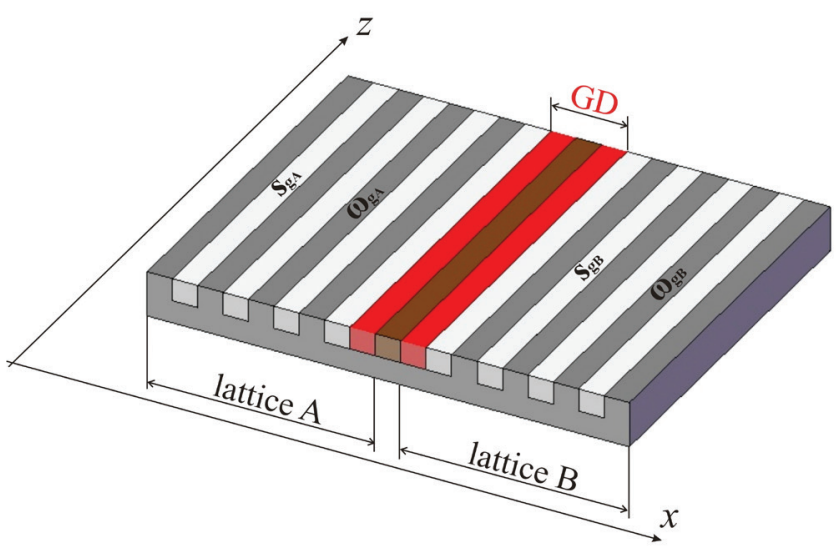

Figure 1. Schematic representation of the system.

Parameters $\omega_{g A}$ and $\omega_{g B}$ (Figure 1) represent the width of the WGs in sub-lattices $A$ and $B$, respectively, whereas $S_{g A}$ and $S_{g B}$ represents the distance between corresponding neighbouring WGs. Red colour shows the GD which consists of two WGs (the first WG in lattice $A$ and the first WG in lattice $B$ ) and the interface between two lattices.

Light propagation, through the system presented in Figure 1, has been modelled by the paraxial time-independent Helmholtz equation [3]:

$i \frac{\partial E}{\partial z}+\frac{1}{2 k_{0} n_{0}} \frac{\partial^{2} E}{\partial x^{2}}+k_{0} n_{0} n_{n l}(x) E=0$,

where $z$ is the propagation coordinate, $E(x, z)$ represents the component of the light electric field in the $z$-direction,

\footnotetext{
* Author address: Marija Stojanović Krasić, University of Niš, Faculty of Technology, Bulevar Oslobođenja 124, 16000 Leskovac, Serbia

E-mail: marijastojanovickrasic@gmail.com

The manuscript received: February, 28, 2017.

Paper accepted: March, 23, 2017.
} 
$k_{0}=2 \pi / \lambda$ is the wave number, $n_{0}$ is the refractive index of the substrate and $\lambda=532 \mathrm{~nm}$ is the wavelength of light. The lattice is prepared along the transverse direction and the lattice system properties are modelled by functional dependence of the refractive index on system parameters in the form:

$n_{n l}(x)=-\frac{1}{2} n_{0}^{2} r E_{p v} \frac{|E|^{2}}{I_{d}+|E|^{2}}$,

Where $E_{p v}$ is the photovoltaic field, $r$ is electro-optic coefficient, $I_{d}$ is dark irradiance. Dark irradiance is the parameter of the material proportional to the number of thermally generated photons in non-lighted material. In order to model the equation (1) numerically, we need to introduce dimensionless variables $\zeta=k_{0} x, \eta=k_{0} z$ and then the Eq. (1) can be rewritten in the following dimensionless form:

$i \frac{\partial \psi}{\partial \eta}+\frac{1}{2 n_{0}} \frac{\partial^{2} \psi}{\partial \zeta^{2}}+\gamma \frac{|\psi|^{2}}{1+|\psi|^{2}} \psi=0$

In the following, the relative nonlinearity strength is $\Gamma=y / \gamma_{0}$ with $\gamma_{0}=0.0001 \approx n_{0}^{3} E_{p v} r / 2$. The light propagation is numerically simulated by the split-step Fourier method [8].

\section{Results and discussion}

The model we have analyzed is experimentally feasible [9] and in this regard one uses selective copper or iron doped lithium - niobat, $20 \mathrm{~mm}$ long sample. In our system WGs are $5 \mu \mathrm{m}$ and $4 \mu \mathrm{m}$ wide in the lattices $A$ and $B$, respectively. The distance between WGs is $4 \mu \mathrm{m}$ and has the same value in both lattices. The width of the interface (the distance between the lattices) is $3.3 \mu \mathrm{m}$. A FWHM of the initial Gaussian beam is $4.3 \mu \mathrm{m}$.

The changeable parameters in our study are the position of the input beam, its transverse kick and the strength of nonlinearity. The transverse kick is the inclination of the beam to the axis of the WG propagation.

A structural difference of two lattices causes the asymmetry of the potentials of lattices. The light propagation through the linear composite lattice (a linear case in the following) has already been analyzed [10]. Here we compare the light propagation through the linear and nonlinear composite lattice (the last is noted as a nonlinear case in the following).

Firstly, we have performed a simulation with light launched into the $1^{\text {st }}$ WG in the lattice $A$. One can observe that light is captured into the WG where it is initiated (Figures 2a and 2b). Smaller values than 1.35 of the nonlinearity strength give weaker capturing, and by increasing the nonlinearity strength it becomes more efficient until it reaches the optimum value of 1.35. Above that value, capturing is weaker again. This behaviour is common for lithium - niobat and other materials with sat- urable nonlinearity, and is presented in Figures $2 a$ and $2 b$. These Figures differ by the nonlinearity strength $\Gamma$.

In Figure 2a, nonlinearity strength is 1.35 , while in Figure $2 b$, it is 5 . Nonlinearity strength $\Gamma=1.35$ is taken because it gives the best capturing results, while $\Gamma=5$ is taken randomly and it shows what happens with its higher values. Due to the higher potential of lattice $B$, the light launched into the first WG in lattice $A$ is confined. On the left side of the GD, there is no restriction of such kind and a small amount of energy can be seen, in the breathing form, at the first neighbouring WG on the left side of the GD.

By comparing the nonlinear case (see Figures 2a and $2 \mathrm{~b}$ ) with the linear one (see Figure 2. c) it can be concluded that the nonlinearity is a dominant effect that keeps the light located at the position where it is launched. When light is initiated into the $1^{\text {st }} W G$ in lattice A, part of the energy diffracts through the same lattice. A small part of the energy is captured at the $1^{\text {st }}$ WG in lattice $B$ and there is a certain amount of diffracted energy through lattice $B$, as well.

Figures $2 d$ and $2 e$ show the light launched into the $1^{\text {st }} W G$ in lattice $B$ for different nonlinearity, $\Gamma=1.35$ and $\Gamma=5$, respectively. Because of the asymmetric lattices potentials of lattices $A$ and $B$ and higher potential of lattice $B$, the light propagates through the $1^{\text {st }} W G$ in lattice $B$ (i. e. it is captured there) when light is launched into it (see Figure 2d). In Figure 2d light is captured at the 1st WG in lattice $B$ while some part of the energy is located at the $1^{\text {st }} W G$ in lattice $A$ and also covers the interface of the lattices. For a higher value of the nonlinearity strength $(\Gamma=5)$, light uniformly covers both WGs (1 $1^{\text {st }}$ in lattice $A$ and 1 st in lattice B) around the interface and the interface also (see Figure 2. e). In the linear case (Figure 2f) light is dominantly captured at the $1^{\text {st }} W G$ in lattice $B$ because of higher potential in lattice $B$ and the absence of nonlinearity. Linearity also enables the part of energy which is not captured to diffract through lattice $B$.

When light is launched into the $2^{\text {nd }}$ WG in lattice $A$, it gets captured at the initial position and at the certain point of its propagation it starts to travel through the $1^{\text {st }}$ WG in lattice $A$ (see Figure $3 a$ and $3 b$ ). The reason for this behaviour might be a mutual influence of nonlinearity and the deformed lattice potential. Deformed lattice potential is caused by joining two structurally different lattices which possess two different potentials. Figures $3 \mathrm{a}$ and $3 \mathrm{~b}$ correspond to $\Gamma=1.35$ and $\Gamma=5$, respectively. In the linear case (Figure 3c) the light is reflected from the interface, and after reflection it continues to travel through lattice $A$.

When the light is launched into the $2^{\text {nd }} W G$ in lattice $B$ (Figures $3 d$ and $3 e$ ) due to the nonlinearity which overcomes the influence of deformed potential in the vicinity of $\mathrm{GD}$, the light is captured at the position where it is started. By comparing Figure 3d and Figure 3e which differ only by nonlinearity strength, it is evident that capturing is better for $\Gamma=1.35$. In the linear case, when light is launched into any of the WGs, light tends to diffract. But when the light is 

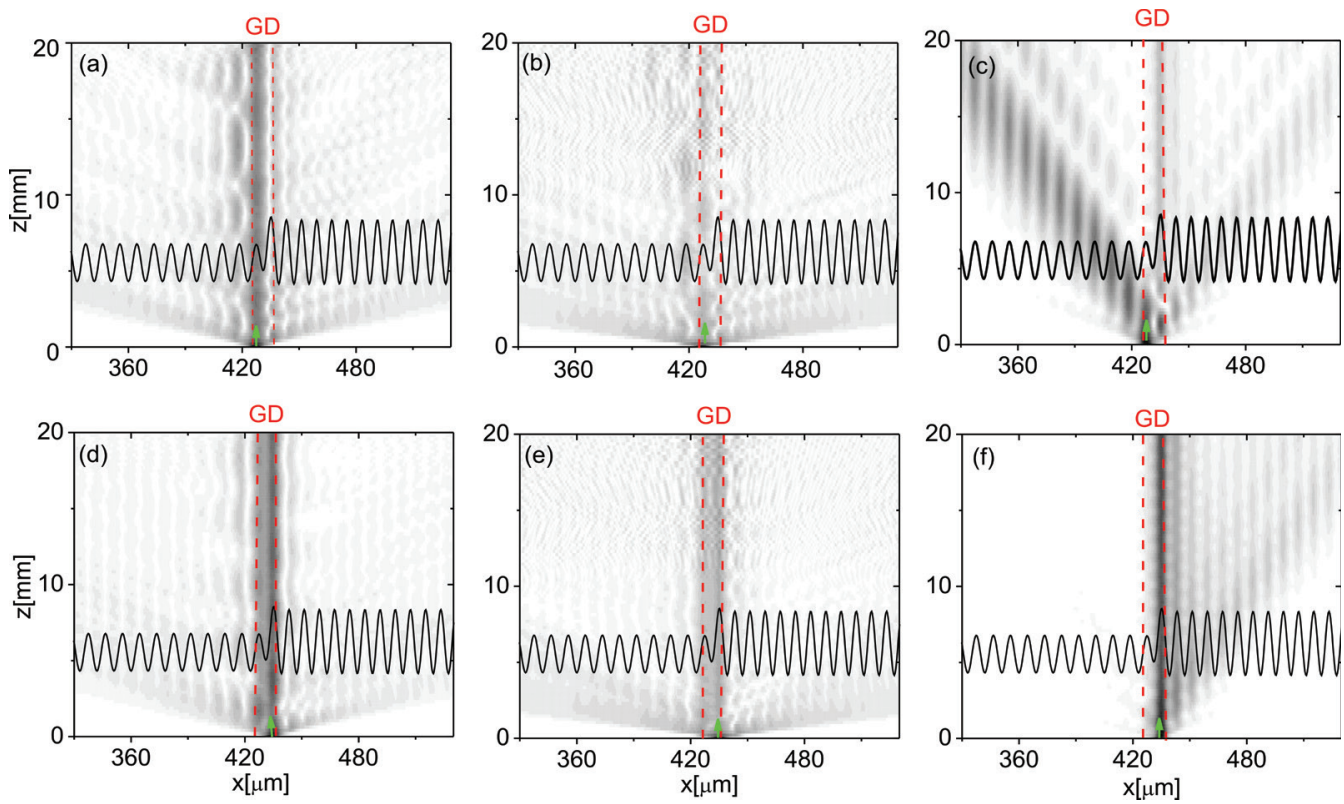

Figure 2. 2D plot of the average beam intensity profiles, the incident beam enters the $1^{\text {st }} \mathrm{WG}$ in lattice A with nonlinearity strength: (a) $\Gamma=1.35$; (b) $\Gamma=5$; (c) $\Gamma=0$. The incident beam enters the $1^{\text {st }} W G$ in lattice B with nonlinearity strength: (d) $\Gamma=1.35$; (e) $\Gamma=5$; (f) $\Gamma=0$. Red line shows the position of the $\mathrm{GD}$, while the green arrow denotes the position of the central part of the incident light beam. Black curve denotes the lattice potential.
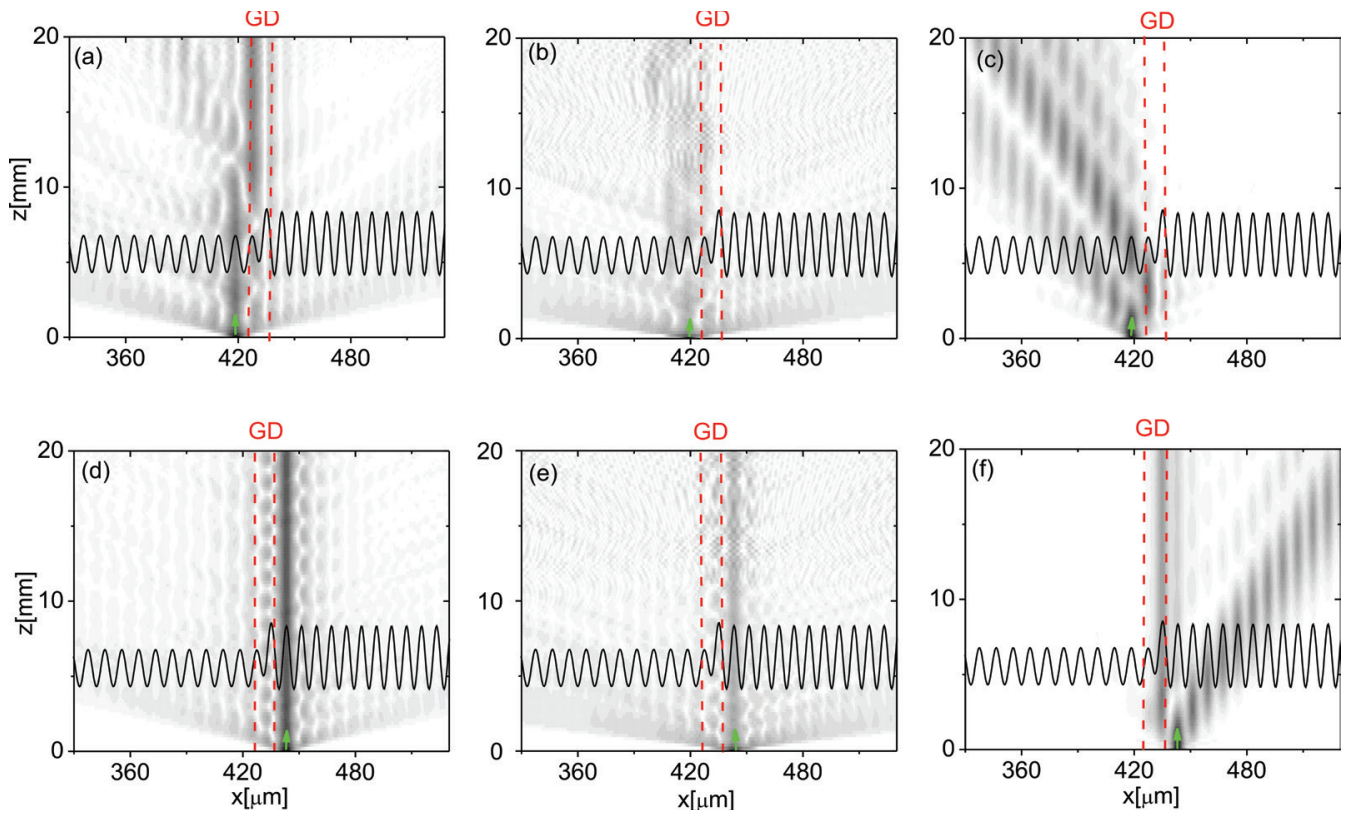

Figure 3. $2 \mathrm{D}$ plot of the average beam intensity profiles, the incident beam enters the $2^{\text {nd }} W G$ in lattice A with nonlinearity strength: (a) $\Gamma=1.35$; (b) $\Gamma=5$; (c) $\Gamma=0$. The incident beam enters the $2^{\text {nd }}$ WG in lattice $B$, with nonlinearity strength: (d) $\Gamma=1.35$; (e) $\Gamma=5$; (f) $\Gamma=0$. Red lines depict the position of the GD, while the green line denotes the position of the central part of the light beam. Black curve marks the lattice potential.

We wonder how nonlinear interface affects a transversely kicked light beam. We obtained the transmission of light for transverse kick (see Figures 4a and 4b). There is no difference whether the light is launched in lattice $A$ and the kick is directed towards lattice $B$, or the light is launched in lattice $B$ and the kick is directed towards lattice $A$ (see Figures $4 a$ and $4 b$ ). It is also possible to obtain partial reflection (mixed with transmission) for transverse kick, of (Figures 4c and 4d). 

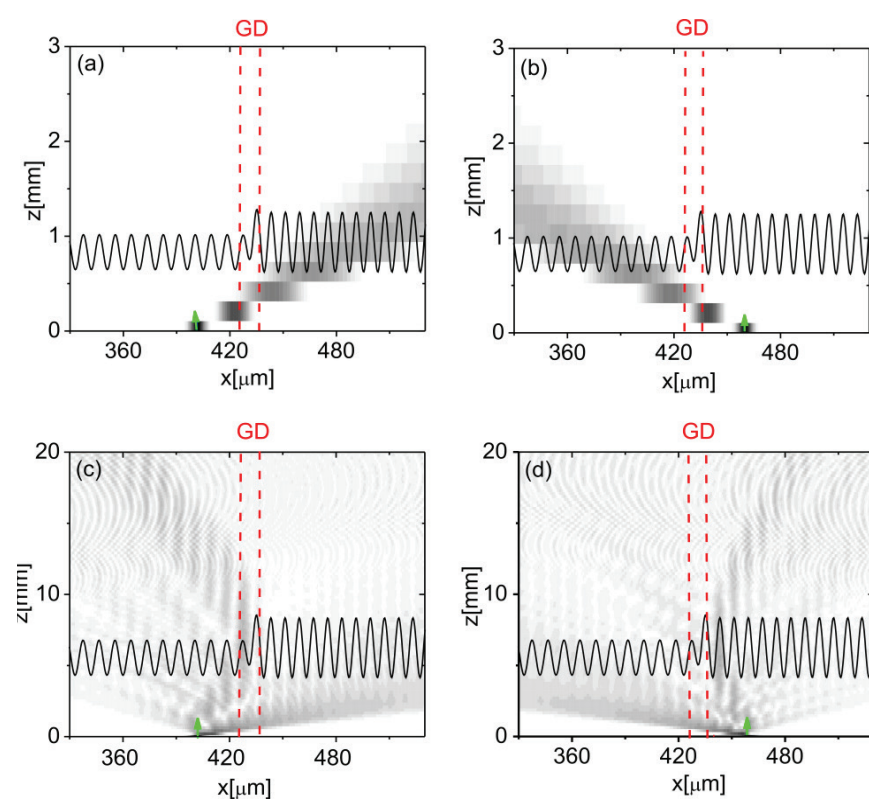

Figure 4. 2D plot of the average beam intensity profiles, nonlinearity strength is $\Gamma=1.35$, the transverse kick is incident beam enters the $4^{\text {th }} W G$ in the lattice: (a) $A$; (b) $B$. Transverse kick is incident beam enters the $4^{\text {th }}$ WG in the lattice (c) $A$; (d) $B$. Red lines show the position of the GD, while the green line denotes the position of the light beam. Black curve depicts the lattice potential.

\section{Conclusion}

In this paper we investigated the influence of a geometric defect formed at the junction between two different nonlinear lattices on the light propagation through the lattice system. The influence of different strength of nonlinearity on the light beam propagation was analyzed and the results were compared with the results obtained for the linear composite photonic lattice, as well. Depending on the initial beam parameters, i. e. its initial position and transverse kick, different regimes of the light propagation were identified, such as: capturing of light, transmission, partial reflection and transmission. These findings may be useful in terms of switching, tunnelling and filtering of the light beam.

\section{Acknowledgment}

The authors thank the Ministry of Education, Science and Technological Development of the Republic of Serbia (Project No. III 45010). The authors also thank Dr. Milutin Stepić for useful comments during the preparation of the manuscript.

\section{References}

[1] J. D. Joannopoulos, S. G. Johnson, J. N. Winn, R. D. Meade, Photonic Crystals; Molding the flow of light, 2nd Edition, Princeton University Press, New Jersey 2008, p. 35.

[2] J. D. Joannopoulos, R. Pierre, V. S. Fan, Photonic
Crystals: putting a new twist on light, Nature, 386(3) (1997) $143-149$.

[3] S. Suntsov, K. G. Makris, D. N. Christodoulides, G. I. Stegeman, R. Morandotti, M. Volatier, V. Aimez, R. Ares, E. H. Yang and G. Salamo, Optical spatial solitons at the interface between two dissimilar periodic media: theory and experiment, Optics Express 16(14) (2008) 10480 10492.

[4] S. Suntsov, K. G. Makris, D. N. Christodoulidess, G. I. Stegeman, R. Morandotti, M. Volatier, V. Aimez, R. Arés, C. E. Rüter, D. Kip, Optical modes at the interface between two dissimilar discrete meta - materials, Optics Express 15(8) (2007) 4663 - 4670.

[5] S. Kuzmanović, M. Stojanović Krasić, D. Milović, M. Miletić, A. Radosavljević, G. Gligorić, A. Maluckov, M. Stepić, Light propagation inside 'cavity' formed between nonlinear deffect and interface of two dissimilar one dimensional linear photonic lattices, European Physical Journal D 69 (2015) 207 - 215.

[6] J. G. White, Structural Defects in Inherited and Giant Platelet Disorders, Advances in Human Genetics, 19 (1990) $133-234$.

[7] A. Diaz, J. Maza, F. Vidal, Anisotropy and structural defect contributions to percolative conduction in granular copper oxide superconductors, Physics Review B 55(2) (1997) 1209.

[8] A. Radosavljević, G. Gligorić, A. Maluckov, M. Stepić, D. Milović, Light propagation management by disorder and nonlinearity in one - dimensional photonic lattices, Journal of the Optical Society of America B, 30(8) (2013) $2340-2347$.

[9] P. P. Beličev, I. Ilić, M. Stepić, A. Maluckov, Y. Tan, F. Chen, Observation of linear and nonlinear strongly localized modes at phase - slip defects in one - dimensional photonic lattices, Optics Letters, 35(18) (2010) 3099 . 3101.

[10] S. Kuzmanović, A. Mančić, M. Stojanović Krasić, Effect of a geometric deffect on light propagation through a composite linear photonic lattice, Facta Universitatis, 13(3) (2015) 163 - 169. 
Izvod

\section{UTICAJ GEOMETRIJSKOG DEFEKTA NA PROSTIRANJE SVETLOSTI KROZ DVE JEDNO-DIMENZIONALNE FOTONSKE REŠETKE}

Marija T. Stojanović Krasić1, Slavica J. Jovanović ${ }^{2}$ Ana M. Mančić ${ }^{3}$

${ }^{1}$ Tehnološki fakultet, Univerzitet u Nišu, Leskovac, Srbija

${ }^{2}$ Prirodno matematički fakultet, Univerzitet u Prištini, Kosovska Mitrovica, Srbija

3 Prirodno matematički fakultet, Univerzitet u Nišu, Niš, Srbija

Numerički je proučavano prostiranje svetlosti kroz spoj dve strukturno različite jedno-dimenzionalne nelinearne rešetke. Napravljeno je poređenje nelinearnog slučaja sa linearnim. U zavisnosti od pozicije upadnog snopa, vrednosti transverzalnog kika i nelinearnosti, dobijeni su različiti režimi prostiranja svetlosti; zarobljavanje svetlosti, transmisija kroz spoj rešetki i parcijalna refleksija od spoja rešetki.
(ORIGINALNI NAUČNI RAD)

UDK 535.317.2:530.182 